\author{
Crossing the Border: International Journal of Interdisciplinary Studies \\ Volume 3; Number 1; 15 January 2015 \\ ISSN 2350-8752 (Print); ISSN 2350-8922 (Online)
}

\title{
EDITORIAL: \\ Interdisciplinary Approach in Teaching Learning and Research
}

Each discipline has a universally recognized core of knowledge, which is subdivided into specific courses called curricula. The curricula of each discipline vary from department to department in terms of numbers of courses offered and the titles of courses. Despite this variety, scholars in a discipline recognize these courses as uniquely the boundary of their discipline. What is discipline, then? We need to define the term 'discipline' before we define interdisciplinary studies.

Simply defined, a discipline is a branch of knowledge or a field of study such as physics, psychology, or history. However, it is equally important to recognize a common misunderstanding about interdisciplinary studies that it replaces the disciplines. Interdisciplinary studies does not replace the disciplines. Rather, it is complementary to the disciplines and relies heavily upon them. Disciplines are the essential foundation stones, which make interdisciplinary studies possible.

An interdisciplinary approach, through the knowledge of interdisciplinary studies, helps foster critical thinking and leads to a natural connection between theory and practice. It is associated with looking at the same issue/s from different perspectives. For instance, the spread of HIV/AIDS can be interpreted differently. An economist would say its cause to be poverty; a medical doctor would say because of unsafe sex; a lawyer would say due to lack of law enforcement; and so on. Similarly, most interdisciplinary approach examines issues that are the focus of several disciplines. We can take another example: the post-9/11 attack in the United States is an interdisciplinary problem because it is a religious problem, an economic problem, a racial problem, and a cultural problem. In addition, the problem of the post-/9/11 attack is near the center of several disciplines, not out on the periphery.

In fact, there is no single answer to all the problems. But from an interdisciplinary perspective, the problem is because of all possible causes and its remedy would involve each and every aspect of human activities. Thus, this approach tries to integrate various interpretations of the same phenomena that are generated from each of the disciplinary perspectives. It identifies and blends knowledge from relevant disciplines so as to make possible a more comprehensive understanding of the problem, or question at hand rather than relying solely on a single discipline. For example, a single disciplinary perspective cannot possibly explain the complex phenomenon of the problems like HIV/AIDS or/and the 9/11 attack much less craft a comprehensive solution to them. A comprehensive understanding of the problem requires using expertise from the disciplines of history, political science, anthropology, sociology, law, economics, religion, and psychology. This process adds that the work of integrating knowledge is also about reaching a practical goal as opposed to an end in itself. Here, the emphasis is on the practical, on real-world problem-solving process of interdisciplinary approach.

The term 'interdisciplinary approach' is usually used in the field of teaching learning. Interdisciplinary teaching learning has now become far more common at all aca- 


\section{Crossing the Border: International Journal of Interdisciplinary Studies}

demic levels. Both teachers and students have realized that all disciplines can come together at a place and all commonly make connections. It brings together two or more disciplines, in a way that they interact with each other and have effects on each other's perspectives as well. Sometimes it happens that it is more than merely multidisciplinary because of an attempt to think through the relations among various disparate disciplines' explanations, which need to be elaborated in a greater detail.

Apart from the use of interdisciplinary approach in teaching learning, it is also an important tool for research. In higher learning, the interdisciplinary approach is often used in research. Traditionally, students are encouraged to pick a field of study fairly early in their university careers. Students may, however, find that their interests span a variety of different academic areas.

Interdisciplinary approach, in teaching learning and research, focuses on the methodologies, interpretive tools, and language of several disciplines of a central problem, issue, or theme. The present edition of Crossing the Border: International Journal of Interdisciplinary Studies is an example of the application of this approach. The articles included in this issue deal with different issues from different perspectives.

The first article entitled "National Geographic Magazine and the Power of Media: How an Elite Society Influenced American Perception" by Michelle Welsch deals with the role of print media on the reading public, which is an interdisciplinary approach to media studies. It endeavors to promote the study and critique of contemporary culture by using experimental approaches to interdisciplinary print-based research.

However, Krishna P. Pandey's article "Karl Polayni, Market Economy and Economic Liberalisation in Nepal," Pramila Neupane/ Jeet Bahadur Sapkota’s article "Development Impacts of Globalization and Education: Evidence from the Asia-Pacific Countries" and Antonella Delle Fave/ Fausto Massimini's article "Cultural Change and Human Behavior: Evolution or Development?" discuss the effects of global movement such as liberalization and globalization into day to day activities of human beings. These articles bring diverse disciplines together to synthesize the problem of modernizing process of the world.

Yajna Prasad Timilsina's "Chronological Trend of Climate in the Lumle Village Development Committee from Kaski District, Nepal" and Sadhana Pradhanang Kayastha's "Arsenic Contamination in the Deep and Shallow Groundwater of Bara District, Nepal" are two research papers included in this issue that integrate the understanding of the impact of climate change on human life. They use interdisciplinary approach to research on an issue from various other points of view.

Radha Devi Sharma, in her article "Sexual Transgression for Power and Identity: A Glimpse on Shakespeare's Twelfth Night" take up the subject of feminism and sexuality to analyze literary works such as Shakespeare's famous play Twelfth Night. She takes the help of an interdisciplinary approach to study a discipline like literature. But Prakash Upadhyay, in his article "Reforms and Changes in Nepal: Political-Sociological Perspectives on State-Restructuring Process in the Post-Democratic Period," has applied political-sociological perspective to understand a political issue such as the re-structuring of Nepali state. Yet another article by Asis De and Abhijit De entitled "Acupuncture and Modern Medicine" combines two aspects of medical science: one is traditional and the other is modern, which is a good example of applying the interdisciplinary approach to deal with a problem, or an issue. 